\title{
Silent domains are assembled continuously from the telomere and are defined by promoter distance and strength, and by SIR3 dosage
}

\author{
Hubert Renauld, Oscar M. Aparicio, Paul D. Zierath, Barbara L. Billington, Sanjay K. Chhablani, \\ and Daniel E. Gottschling \\ Department of Molecular Genetics and Cell Biology, The University of Chicago, Chicago, Illinois 60637 USA
}

\begin{abstract}
In Saccharomyces cerevisiae, telomeres repress transcription of genes located nearby. This region-specific gene inactivation is thought to involve the packaging of telomeric domains into silent chromatin. To gain insight into the mechanism of telomeric silencing, a genetic assay to examine the spread of silencing along the distal right arm of chromosome $\mathrm{V}$ was developed. The frequency of silencing a telomere-adjacent URA3 gene decreased with increasing distance of the gene's promoter from the telomere, irrespective of transcriptional orientation. The distance over which telomeric silencing of URA3 was observed was extended by weakening the gene's promoter-specifically, by deleting PPR1, the trans-activator of URA3. The silent telomeric domain was extended even farther by increasing the gene dosage of SIR3. These results suggest that a gene's promoter is a key determinant in controlling silencing on that gene and that SIR3 is a crucial component of the silent chromatin domain that initiates at the telomere and is assembled inwardly along the yeast chromosome. Finally, silencing is not observed on the centromeric side of an actively transcribed telomeric gene, demonstrating that the repressed telomeric domain is propagated continuously along the DNA. Taken together, these data reflect the complex and dynamic organization of eukaryotic genomes into functionally distinct regions.
\end{abstract}

[Key Words: Saccharomyces cerevisiae; silencing; heterochromatin; gene expression]

Received March 3, 1993; revised version accepted April 27, 1993.

The eukaryotic genome is organized into regions distinct in their structure and function. Heterochromatin, which defines one such structural region, is condensed throughout the cell cycle while its counterpart, euchromatin, is more diffuse in appearance during interphase (Heitz 1928, as cited in Brown 1966). Chromosomal regions also differ functionally, as the expression of a eukaryotic gene can be profoundly affected by its chromosomal position. This phenomenon, chromosomal position effect, is observed in many eukaryotes (for review, see Lima-de-Faria 1983) and has been studied extensively in Drosophila melanogaster (for extensive reviews, see Lewis 1950; Baker 1968; Spofford 1976). When genetic rearrangements place euchromatic segments of the genome into or near heterochromatin, the expression of a translocated euchromatic gene is altered in a population of cells: Some cells express the gene, whereas others do not. Thus, a mosaic or variegated phenotypic pattern is produced.

Chromosomal position-effect phenomena can spread over great distances in the genome; for example, in Drosophila, genes located as far away as 80 chromosome polytene bands $(\sim 2000 \mathrm{kbp})$ are still subject to positioneffect variegation (PEV) (Demerec 1940). This spreading effect is thought to reflect the dynamic nature of assembly of heterochromatin over a locus (for review, see Zuckerkandl 1974; Spofford 1976). When heterochromatin assembles far enough to include a locus, the gene within it is inactivated.

In Saccharomyces cerevisiae, chromosomal domains have been identified that exert position effect: the cryptic mating-type loci, $H M L$ and $H M R$, and telomeres (for review, see Laurenson and Rine 1992; Sandell and Zakian 1992). Genes located near or within these domains may be transcriptionally silenced and exhibit phenotypic variegation (Klar et al. 1981; Nasmyth et al. 1981; Schnell and Rine 1986; Mahoney and Broach 1989; Gottschling et al. 1990). At least six modifiers of position effect are shared between the $H M$ loci and telomeres. A mutation in SIR2, SIR3, SIR4, NAT1, ARD1, or HHF2 (which encodes histone $\mathrm{H} 4$ ) reduces or abolishes silencing at telomeres, $H M L$, and $H M R$ (Hopper and Hall 1975; Haber and George 1979; Klar et al. 1979, 1981; Ivy et al. 1986; Rine and Herskowitz 1987; Whiteway et al. 1987; 
Kayne et al. 1988; Mullen et al. 1989; Megee et al. 1990; Park and Szostak 1990; Aparicio et al. 1991). The involvement of histone $\mathrm{H} 4$ and the observation that the $H M$ loci and telomeres are refractory to DNA modifications in vivo in a SIR-dependent manner point to chromatin structure as being involved in silencing the $H M$ loci and telomeres. Specifically, this chromatin structure is thought to hinder access of transcription factors to these loci (Nasmyth 1982; Kostriken et al. 1983; Klar et al. 1984; Gottschling 1992; Singh and Klar 1992).

The spreading of position effect also occurs in yeast (Abraham et al. 1984; Feldman et al. 1984). Genes located up to $\sim 4.9 \mathrm{kbp}$ from a telomere still are subject to position effect, whereas no silencing is detected at loci $\sim 20 \mathrm{kbp}$ from the chromosome end (Gottschling et al. 1990). Additionally, insertion of a 30-kbp Ty array between the $\mathrm{E}$ and I sites (cis-acting elements required for silencing) at $H M L \alpha$ relieves silencing at this locus. However silencing is re-established when this array is reduced to a single 7-kbp Ty (Mastrangelo et al. 1992). Thus, there is a limit to the size of silenced domains at both $H M$ loci and telomeres.

Telomeric silencing in yeast provides an excellent opportunity to study the spread of position effect in a eukaryote, particularly because the initiation site of position effect is known to be the end of the chromosome (Gottschling et al. 1990). In this paper, a quantitative method to examine telomeric position effect was used to identify parameters that modulate spreading. The results provide a molecular and mechanistic insight into the propagation of silencing in yeast, as well as the functional organization of silent chromosomal domains.

\section{Results \\ Silencing of URA3 decreases with increased distance from the telomere}

In an earlier study, we detected telomeric position effect (TPE) in $S$. cerevisiae $4.9 \mathrm{kbp}$ from the left end of a modified chromosome VII (VII-L) by measuring the level of transcriptional repression of a telomere-proximal URA3 when various yeast genes were inserted between $U R A 3$ and the telomere (Gottschling et al. 1990). However, the effect of each inserted sequence on URA3 expression was not exclusively dependent on the size of the insert. To better characterize the spread of TPE in S. cerevisiae, we examined the expression of $U R A 3$ as a function of its distance from a representative telomere, without introducing any new sequences between URA 3 and the end of the chromosome.

A set of isogenic strains was created with URA3 placed at various distances from the right end of chromosome $\mathrm{V}(\mathrm{V}-\mathrm{R})$ (Fig. 1); the normal chromosomal copy of $U R A 3$ is nonfunctional in each strain. At each site of insertion, URA3 was positioned in either transcriptional orientation. This set of strains may be divided into two groups: Those that maintained the original $\sim 6.7-\mathrm{kbp}$ telomere-associated $\mathrm{Y}^{\prime}$ element of $\mathrm{V}-\mathrm{R}$, and those in which the $\mathrm{Y}^{\prime}$ and some adjacent sequences were replaced with a new terminus of $\left(\mathrm{TG}_{1-3}\right)_{\mathrm{n}}$. These $\mathrm{Y}^{\prime}$ elements are middle-repetitive DNA sequences found proximal to some, but not all, yeast telomeres; their function is unknown (for review, see Olson 1991).

Transcriptional repression as a function of distance from the chromosome end was analyzed by determining
Figure 1. Chromosomal constructs used to study telomeric position-effect spreading along V-R. $(A)$ A diagram of the chromosome $V-R$ distal region in a wild-type strain is shown (adapted from Ferguson et al. 1991). The open box and the diffuse dark end represent the $\mathrm{Y}^{\prime}$ subtelomeric element and the telomeric $\left(\mathrm{TG}_{1-3}\right)_{\mathrm{n}}$ repeat, respectively, and are not drawn to scale. Physical location and transcriptional orientation of the RAD 3 and RAD24 genes are indicated by arrows. [The telomere-associated sequence X (Zakian 1989) was not detected by Southern analysis on V-R in the strains used in this study (data not shown). The $\mathrm{X}$ probe was made from an $E c o$ RI-EcoRV fragment, which is presumably common to all X elements (Wright et al. 1992).] The region of V-R cloned into plasmid $\mathrm{pB} 610 \mathrm{H}$ and used in plasmid constructs is underlined and shown in an expanded scale, with a partial restriction map (C. Newlon, pers. comm.). (B) BamHI; (H) HindIII; (K) KpnI, (R) EcoRI. HindIII sites are numbered with respect to the telomere, as indicated by their subscripts. $(B)$ An expanded view of V-R along with a representation of each strain that contained $U R A 3$ (solid box; arrows indicate transcriptional direction) along V-R. Strain designations for both $P P R 1^{+}$and $p p r 1^{-}$derivatives are indicated at right.
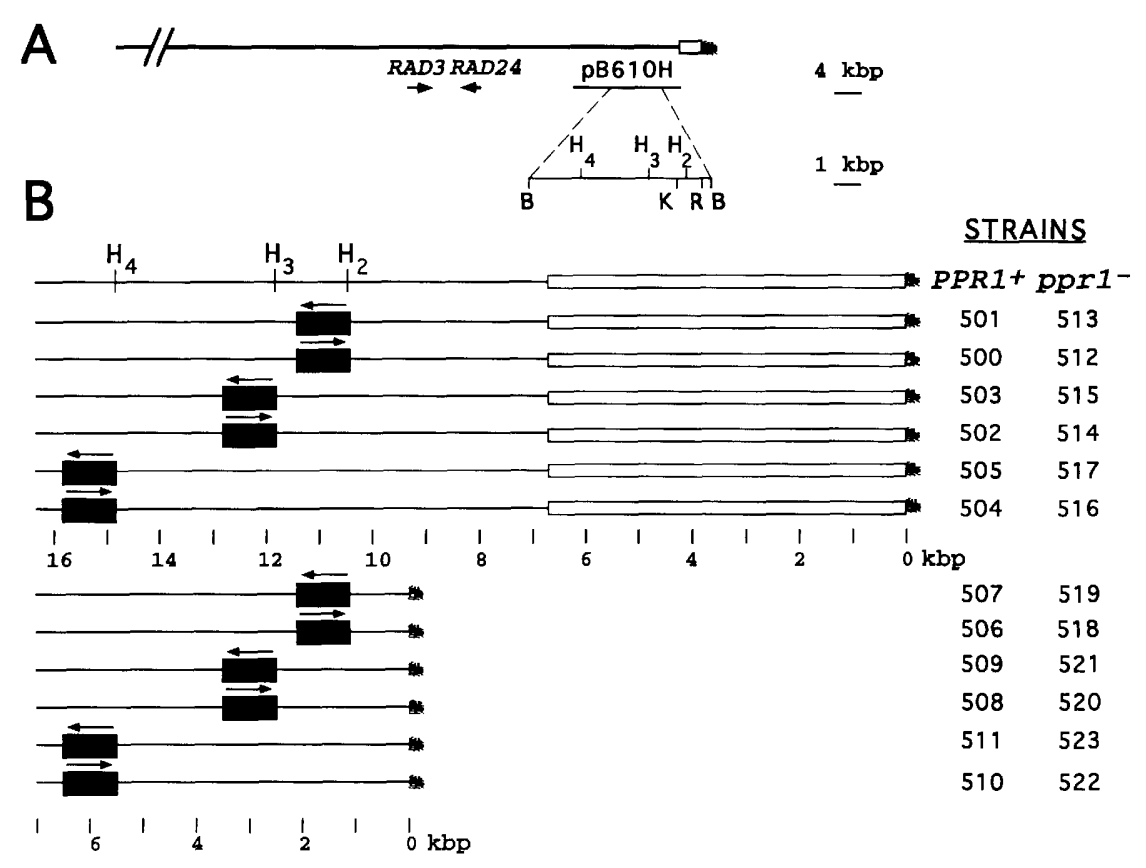
the level of $U R A 3$ silencing in each strain. The level of silencing in a population of cells is quantified by determining the fraction of cells capable of forming colonies on 5-fluoro-orotic acid (5-FOA) medium, 5-FOA is lethal to cells expressing the URA3 gene product (Boeke et al. 1987). In our analysis, the ability of a cell to give rise to a colony on 5-FOA $\left(5-\mathrm{FOA}^{\mathrm{R}}\right)$ indicates that when it was plated onto the medium, the cell contained little or no URA3 gene product. Thus, when URA3 is telomeric, telomere-mediated transcriptional repression enables the cell to grow on 5-FOA (Gottschling et al. 1990).

Quantification of TPE spreading along V-R is summarized graphically in Figure $2\left(\mathrm{PPR}^{+}{ }^{+}\right)$, where the fraction of $5-\mathrm{FOA}^{\mathrm{R}}$ cells is plotted versus the distance of the URA3 promoter from the telomere. A continuous gradient in frequency of silencing was observed, with the highest frequency occurring at the most telomere-proximal position. Repression was no longer detected when the $U R A 3$ promoter was located $3.5 \mathrm{kbp}$ away from the telomere. The steady decrease in frequency of repression with respect to promoter distance from the telomere suggested that the position of the URA3 promoter was the key element in determining repression; transcriptional orientation with respect to the telomere did not appear to be significant in regulating URA3 expression (Fig. 2). Finally, in strains with a $\mathrm{Y}^{\prime}$ element between the URA3 gene and the V-R telomere (UCC500-505), no repression was detected at the tested distances of $10-16 \mathrm{kbp}$ from the telomere (data not shown).

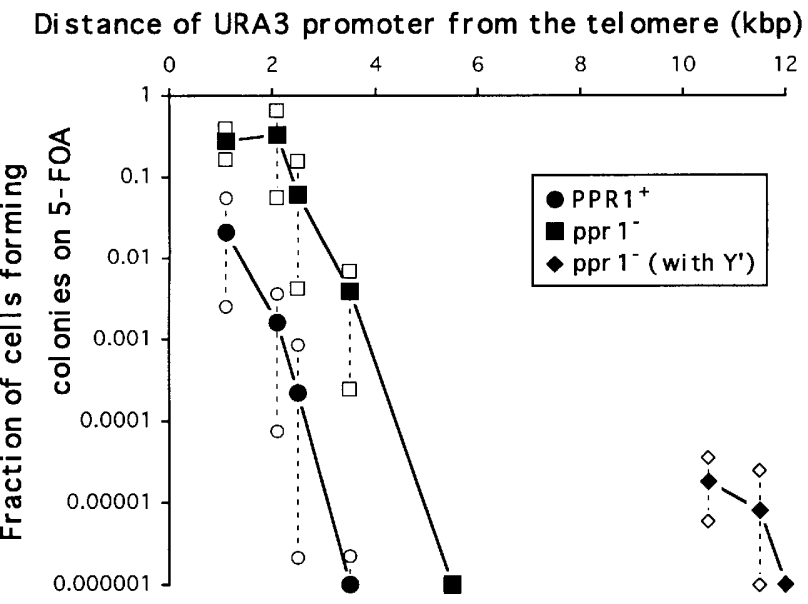

Figure 2. The effect of promoter location and strength on silencing of a telomeric URA3. Transcriptional repression of $U R A 3$ in the strains described in Fig. $1 \mathrm{~B}$ was determined by measuring resistance to 5-FOA. Data points from strains with $\mathrm{V}-\mathrm{R}$ still bearing the original subtelomeric $\mathrm{Y}$ ' sequence are labeled "with Y'." PPR1 was either present (PPR $1^{+}$) or absent $\left(p_{p r} 1^{-}\right)$in the strains examined. Solid and open symbols are the mean and the extremes of the distribution, respectively, of the ratios of colonies formed on 5-FOA medium compared with colonies formed on nonselective medium, from a minimum of four independent trials. Values at or below $10^{-6}$ are beyond the sensitivity limit of the assay and are considered as zero.
Absence of a trans-activator increases the extent of TPE spreading

If promoter distance from the telomere is a primary determinant for governing TPE spreading, then weakening the promoter might result in an increase in spreading. To test this idea, $p p r 1^{-}$derivatives of the strains described above, with URA3 at various distances from the telomere, were created. [PPR1 is a trans-activator protein that enhances expression of the URA3 gene (Loison et al. 1980; Roy et al. 1990).] As shown in Figure 2, repression was more frequent at each location of URA3 and detectable over a greater distance from the telomere in $p p r 1^{-}$ than in $P P R 1^{+}$strains. Thus, the range over which TPE spreads seems to be inversely related to the promoter strength of the gene being assayed. Similarly, deleting GCN4, the HIS3 trans-activator (Hope and Struhl 1985; Hinnebusch 1988), reduced the ability of strains carrying a telomeric copy of HIS 3 to form colonies on medium lacking histidine (Fig. 5, below; data not shown), indicating that this effect is not specific to URA3.

In the $p p r 1^{-}$strains with the $\mathrm{Y}^{\prime}$ element present at $\mathrm{V}-\mathrm{R}$, a small fraction of 5-FOA ${ }^{\mathrm{R}}$ cells were reproducibly observed in the two strains in which the URA3 promoter is $\sim 11$ and $12 \mathrm{kbp}$ from the telomere (Fig. 2; see Fig. 1, UCC513 and UCC512). Southern analysis revealed no change in chromosome structure between URA3 and the telomere in these strains (data not shown). These results contrast with the data for strains lacking the $\mathrm{Y}^{\prime}$ element on V-R (UCC518-523), in which no repression was detected beyond $\sim 6 \mathrm{kbp}$ from the V-R telomere. Thus, it seems that $6.7 \mathrm{kbp}$ of $\mathrm{Y}^{\prime}$ sequence has a greater ability to sustain telomere-dependent silencing than the same length of unique $\mathrm{V}-\mathrm{R}$ sequence.

\section{Overexpression of SIR3 enhances TPE spreading}

The gene products of SIR2, SIR3, and SIR4 are required for TPE, and it has been postulated that one or more of them is a structural component of silent yeast chromatin (Nasmyth 1982; Ivy et al. 1986; Marshall et al. 1987; Rine and Herskowitz 1987; Alberts and Sternglanz 1990; Johnson et al. 1990; Aparicio et al. 1991; Stone et al. 1991). To examine whether the normal cellular level of SIR2, SIR3, or SIR4 limits the range of silent telomeric domains, we tested whether introduction of multiple copies of the SIR2, SIR3, or SIR4 genes would increase the spread of TPE. Only raising SIR3 copy number enhanced position-effect spreading on telomere-adjacent genes (Figs. 3A and 6). No phenotype was observed in strains transformed with a multicopy plasmid carrying SIR2 (data not shown). Increasing SIR4 dosage relieved silencing on telomeric genes (data not shown); a similar effect has been observed previously at a weakened $H M R$ (Sussel and Shore 1991).

The effect of SIR3 overexpression was quantified in the sets of strains previously described (Fig. 1B, UCC500-523). Increased dosage of SIR3 raised the frequency of $U R A 3$ silencing in each strain (Fig. 3A). In ppr1- $1^{-}$strains overexpressing SIR3 on a high-copy plas- 
A

Distance of URA3 promoter from the telomere (kbp)

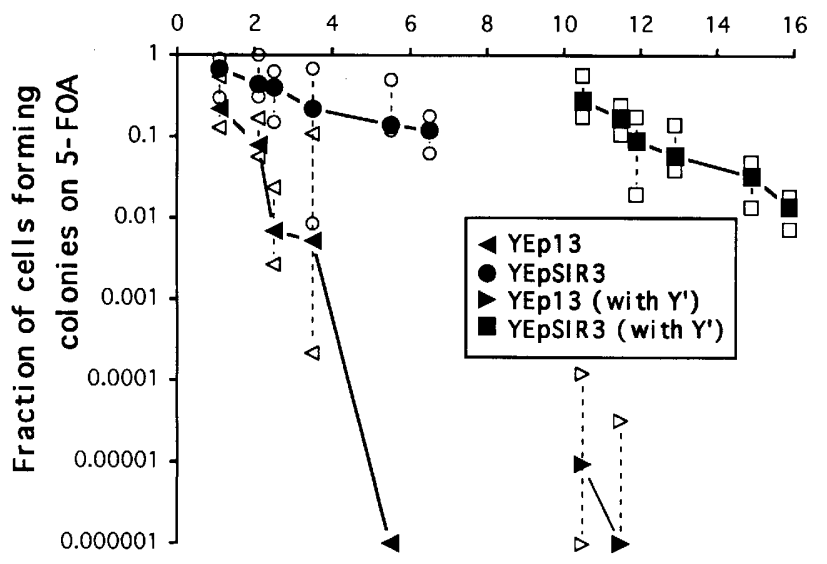

B Distance of URA3 promoter from the telomere (kbp)

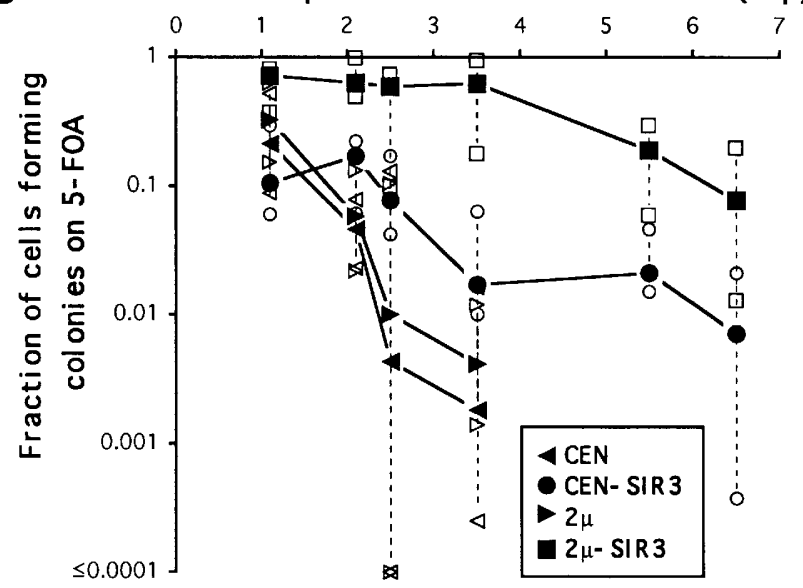

Figure 3. Increased SIR3 gene dosage enhances telomeric position-effect spreading. $(A)$ The ppr1- strains described in Fig. $1 \mathrm{~B}$ were transformed with either YEp13 containing the SIR3 gene (YEpSIR3) or the vector alone (YEp13). Data were collected as in Fig. 2, except that media lacked leucine to maintain the plasmids; the median (solid symbols) and the extremes (open symbols) of at least five independent trials are reported for each data point. $(B)$ Strains UCC518-523 (ppr1-) were transformed with SIR3 carried on a centromeric plasmid (CEN-SIR3), a multicopy plasmid $(2 \mu-S I R 3)$, or with either vector alone (CEN or $2 \mu$ ). To maintain the plasmids, all media lacked tryptophan. Plating efficiencies on 5-FOA medium were recorded and presented as in $A$. Resistance to 5-FOA for UCC523 transformed with either vector alone was at the limit of detection; this data point was not plotted.

mid (YEpSIR3), URA3 was frequently silenced $16 \mathrm{kbp}$ from the telomere (with a $Y^{\prime}$ ), whereas in cells with vector alone (YEp13) no significant silencing was detectable beyond $4 \mathrm{kbp}$. Similar results were obtained in $P P R 1^{+}$ strains transformed with YEp13 or YEpSIR3, although as expected from the data presented in the previous section, URA3 transcription was somewhat less frequently repressed than in the ppr1- $1^{-}$strains (data not shown). Again, the presence of a $Y^{\prime}$ element appeared to facilitate TPE spreading over longer distances than unique chromosomal sequences.

Extrapolation of the "YEpSIR3 with Y" curve (Fig. 3A) suggested that TPE spreading should extend inward $\sim 25$ $\mathrm{kbp}$ from the end of chromosome V-R in the SIR3-overexpressing strains. Consistent with this estimate, URA3 was repressed at $22 \mathrm{kbp}$ from the VII-L telomere when SIR3 was overexpressed (Fig. 6B, below), but URA3 expression was not affected at its normal locus /data not shown), $\sim 120 \mathrm{kbp}$ from telomere V-L (Mortimer et al. 1992). No increase in telomeric silencing was detected in strains transformed with plasmids carrying mutant alleles of SIR3, indicating that propagation of telomeric silencing is dependent on functional SIR3 (data not shown). These results are consistent with SIR3 being a limiting component required to assemble repressive telomeric chromatin.

If SIR3 is limiting, the spread of TPE should be very sensitive to SIR3 gene dosage. This hypothesis was tested in $p p r 1^{-}$strains transformed with SIR3 carried either on a centromeric (CEN-SIR3) or a multicopy plasmid $(2 \mu-$ SIR 3$)$, or with the vectors alone $(\mathrm{CEN}$ and $2 \mu$; Fig. $3 \mathrm{~B}$ ). With a single-copy plasmid (CEN-SIR3), the spreading effect was less enhanced than with a high-copy plasmid $(2 \mu-$ SIR 3$)$ but greater than with either vector alone (Fig. 3B). Hence, the results indicate that SIR3 dosage limits the spread of yeast telomeric position effect.

Increased SIR3 dosage cannot suppress the requirements of SIR2, SIR4, NAT1, ARD1, and histone H4 for TPE

In addition to SIR3, the gene products of SIR2, SIR4, NAT1, ARD1, and HHF2 (histone $\mathrm{H} 4$ ) are required for transcriptional silencing at telomeres (Aparicio et al. 1991). We tested whether the increased dosage of SIR3 could restore TPE in cells deficient for these other proteins. Strains containing URA3 adjacent to the VII-L telomere and defective in each of the aforementioned genes were transformed with a high-copy SIR3 plasmid. In no case did increased levels of SIR 3 restore telomeric silencing (Table 1).

Mutations in SIR1 do not relieve silencing at telomeres, suggesting that SIR1 is not involved in controlling TPE (Aparicio et al. 1991). Consistent with this idea, SIR3 overexpression in sir $1^{-}$strains enhanced TPE spreading, as observed in wild-type strains (Table 1). Because the SIR3 dosage-dependent enhancement of TPE cannot suppress the requirements for SIR2, SIR4, NAT1, $A R D 1$, and histone $\mathrm{H} 4$, it appears that the SIR3 effect operates through the normal mechanism of telomeric silencing, rather than introducing a novel mechanism of silencing.

\section{Silenced chromosomal domains spread continuously from the telomere}

The results presented above suggest that the silenced telomeric domain spreads inward along the chromosome 
Table 1. Increased SIR3 dosage cannot suppress the requirements of SIR2, SIR4, NAT1, ARD1, and histone H4

\begin{tabular}{llcc}
\hline & & \multicolumn{2}{c}{ Fraction 5-FOA } \\
\cline { 3 - 4 } Strain & Genotype & $2 \mu-$ SIR3 & $2 \mu$ \\
\hline UCC1001 & wild type & $0.47(0.29-0.60)$ & $0.35(0.20-0.45)$ \\
UCC3248 & sir2 & $<2 \times 10^{-6}$ & $<2 \times 10^{-6}$ \\
UCC3249 & sir3 & $0.56(0.39-0.73)$ & $<1 \times 10^{-6}$ \\
UCC3250 & sir4 & $<4 \times 10^{-6}$ & $<1 \times 10^{-6}$ \\
UCC2031 & wild type & $0.42(0.33-0.67)$ & $0.55(0.47-0.67)$ \\
UCC2032 & HHF2-gly16 & $<5 \times 10^{-6}$ & $<4 \times 10^{-6}$ \\
UCC2033 & HHF2-gln16 & $<7 \times 10^{-6}$ & $<8 \times 10^{-6}$ \\
UCC2034 & HHF2-gly17 & $<5 \times 10^{-6}$ & $<7 \times 10^{-6}$ \\
UCC18 & wild type & $0.55(0.50-0.60)$ & $<.43(0.37-0.50)$ \\
UCC25 & ard1 & $<36 \times 10^{-6}$ & $<32 \times 10^{-6}$ \\
UCC16 & nat1 & $<50 \times 10^{-6}$ & $<29 \times 10^{-6}$ \\
UCC1003 & wild type & $0.0024(0.0013-0.0036)$ & $<9 \times 10^{-6}$ \\
UCC3243 & sir1 & $0.0021(0.0010-0.0047)$ & $<6 \times 10^{-6}$
\end{tabular}

Shown is resistance to 5-FOA of strains from various backgrounds carrying URA3 at the adh4 locus (UCC1003 and UCC3243) or adjacent to the VII-L telomere (all others). Strains were transformed with a $2 \mu$-derived plasmid carrying no insert (2 $\mu$ : YEp13 in UCC1001, UCC2031, and their derivatives; pHR59-33 in UCC18, UCC1003, and their derivatives) or SIR3 (2 $\mu-S I R 3)$. The relevant genotype of the strains is indicated. Wild type: ARD1, HHF2, NAT1, SIR1, SIR2, SIR3, SIR4. Data were collected as in Fig. 3. The mean of at least three independent trials is presented; the range of values is given in parentheses. For transformants where no FOA resistance was detected, the actual limit of detection of the assay is reported.

in a continuous fashion. To test this idea further, two genes were placed adjacent to one another near the same telomere, and the transcriptional state of the centromere-proximal gene was examined when the telomere-proximal gene was transcriptionally active. If the silenced domain is spread continuously along the chromosome, then the centromere-proximal gene should always be derepressed when the telomere-proximal gene is active. However, if the repressed domain is discontinuous, then the centromere-proximal gene may be in a repressed state even when the telomere-proximal gene is active (Fig. 4).

Both the URA3 and HIS3 genes were inserted near the V-R telomere without a $\mathrm{Y}^{\prime}$ element present; each of the eight possible permutations of URA3 and HIS 3 located near the V-R telomere was constructed (UCC2576-2583; Fig. 5). In addition, three strains were created in which URA3 and HIS3 were located on two different chromosomes (V-R and VII-L), with both genes adjacent to a telomere (UCC2590), with URA3 at a telomere and HIS3 nontelomeric (UCC2589), or the converse situation (UCC2591). To improve the sensitivity of the spreading assay, the promoters of URA3 and HIS 3 were weakened by deleting PPR 1 and GCN4, the genes that encode their respective trans-activators, in each strain. All strains grew in the absence of histidine (Fig. 5 ; - his), indicating that HIS 3 was capable of being expressed at each chromosomal position, although expression was compromised at some telomeric locations (e.g., UCC2577; colony size was small and plating efficiency was reduced on

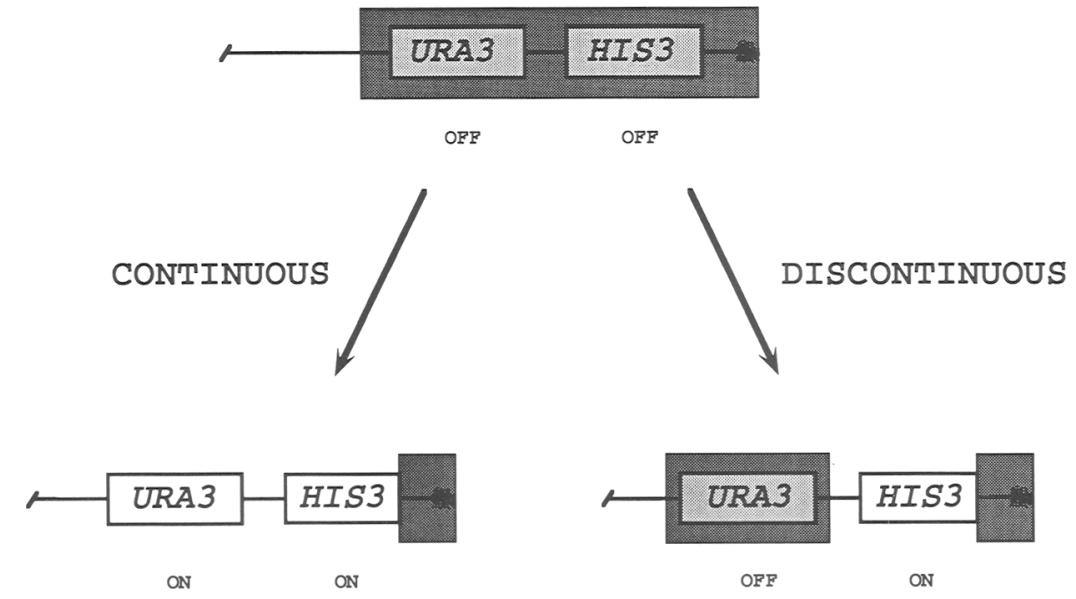

ON
Figure 4. General models for the spreading of silent chromosomal domains. The scheme depicts the rationale used to test whether silencing spreads continuously from yeast telomeres. In this scheme the domain encompassing both genes has the potential to be repressed. If telomeric chromatin spreads continuously from the telomere and the HIS 3 gene is transcriptionally active (ON), URA3 will not be silenced (it is ON). In the discontinuous model, silent chromatin may reinitiate beyond the active $H I S 3$ gene, repressing URA 3 (OFF). The diffuse dark end represents the telomeric $\left(\mathrm{TG}_{\left.1_{-3}\right)_{\mathbf{n}}}\right.$ repeat. The shaded box encompassing the chromosomal sequences depicts the silenced chromosomal domain. 
- his). All strains carrying a telomeric $U R A 3$ gave rise to colonies that grew on fully supplemented 5-FOA medium, reflecting transcriptional repression of $U R A 3$ (Fig. 5 ; FOA).

The test for continuity of the silenced domain along the chromosome from the telomere is presented in the panel labeled FOA - his of Figure 5. In the four strains with both URA3 and HIS3 located near the V-R telomere and HIS3 as the telomere-proximal marker (UCC25762579), no growth was detected on FOA - his medium. That is, when HIS3 was nearer to the telomere and transcriptionally active, URA3 was never transcriptionally repressed. In contrast, when URA3 was telomere-proximal (UCC2580-2583) colonies were obtained on FOAhis, indicating that it was possible for URA3 to be repressed while HIS 3 was active. Thus TPE spreads continuously inward from the telomere. These results also suggest that the spread of silencing can be blocked by transcription of an intervening gene.

Of the four strains with URA3 in the telomere-proximal location, UCC2581 showed conspicuously poor growth on FOA - his. In this strain, the URA 3 and HIS 3 promoters are separated by only $\sim 0.5 \mathrm{kbp}$. In such close proximity it might be difficult to open the HIS 3 chromatin structure without also disrupting the silencing apparatus over $U R A 3$. Another notable result was observed when URA3 and HIS3 were located at different telomeres (UCC2590); robust colonies grew on FOA-his medium, signifying repression at one telomeric locus while the other telomeric marker was expressed. This result indicates that telomeric silencing is locus specific.

We then examined whether the increased spread of silencing mediated by $S I R 3$ overexpression was also continuous. TRP1 and URA3 were inserted $\sim 12.5$ and 22 $\mathrm{kbp}$, respectively, from the VII-L telomere (Fig. 6A). 5-FOA ${ }^{\mathrm{R}}$ colonies were observed only when the cells were transformed with YEpSIR3 (Fig. 6B; FOA-leu); however, no 5-FOA ${ }^{\mathrm{R}}$ was detected if TRP1 was simultaneously expressed in these cells (Fig. 6B; FOA - trpleu). TRP1 expression by itself was only modestly impaired in YEpSIR3 transformants, as demonstrated by their high efficiency of plating on - trp-leu medium. Similar results were obtained when $A D E 2$ (inserted $\sim 9$ $\mathrm{kbp}$ from the same telomere) replaced TRP1 in this experiment (data not shown). Taken together, these observations suggest that SIR3 propagates silencing continuously from the telomere.

\section{Discussion}

We have carried out a systematic characterization of the spreading of TPE in S. cerevisiae. The telomeric position effect in yeast can be considered as a gradient of transcriptional silencing along the chromosome. We postulate that this gradient reflects the limited assembly of a silent chromatin (heterochromatic-like) structure that initiates at the telomere and proceeds continuously inward along the chromosome. In our analysis, the fraction of 5-FOA ${ }^{\mathrm{R}}$ cells provided an estimate of the frequency at which a telomeric $U R A 3$ was located within this repressive structure.

Transcriptional inactivation of a telomeric locus may be viewed as the final product of a reaction in which subunits of silent chromatin are assembled. In a simple model, silencing of a $U R A 3$ gene $6 \mathrm{kbp}$ from the telomere would require six times as many subunits as that needed to silence a URA3 gene located $1 \mathrm{kbp}$ away. If the assembly of telomeric repressive chromatin were a first-
Complete

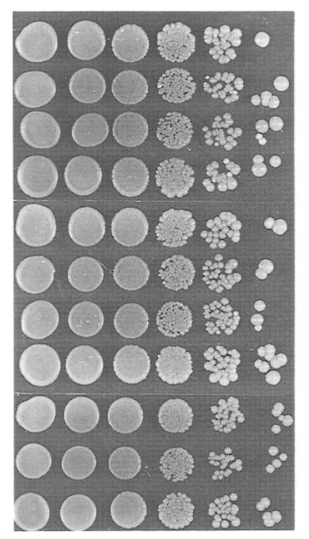

-his

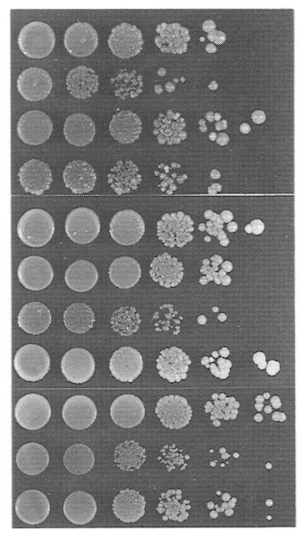

FOA

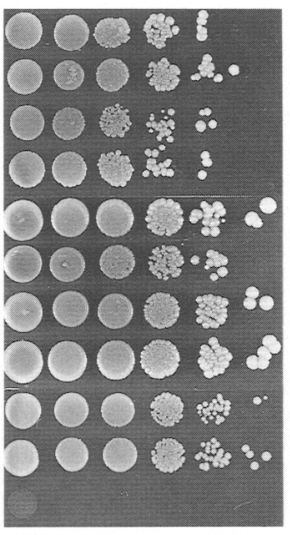

FOA-his

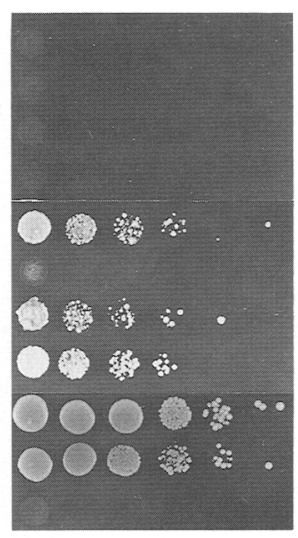

STRAINS

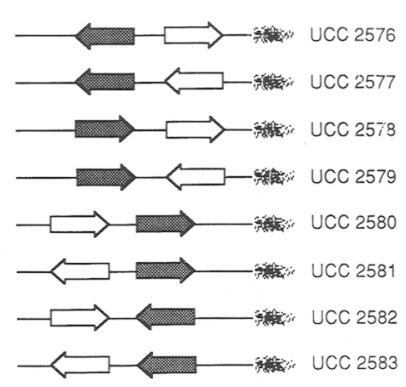

HIS3 (int) VIIL, URA3 (tel) VR UCC 2589 HIS3 (tel) VR, URA3 (tel) VIIL UCC 2590 HIS3 (tel) VR, URA3 (int) VIIL UCC 2591

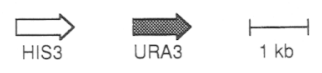

Figure 5. Silenced chromosomal domains spread continuously from the telomere. Cells were pregrown on rich medium, and 10-fold serial dilutions were plated onto nonselective medium (Complete), medium lacking histidine (-his), medium containing 5-FOA (FOA), and medium lacking histidine and containing 5-FOA (FOA-his). The arrows represent the genes and their transcriptional orientation. (tel and int) A telomeric and an internal location on the chromosome, respectively. The V-R telomeric repeat is not drawn to scale. 
A
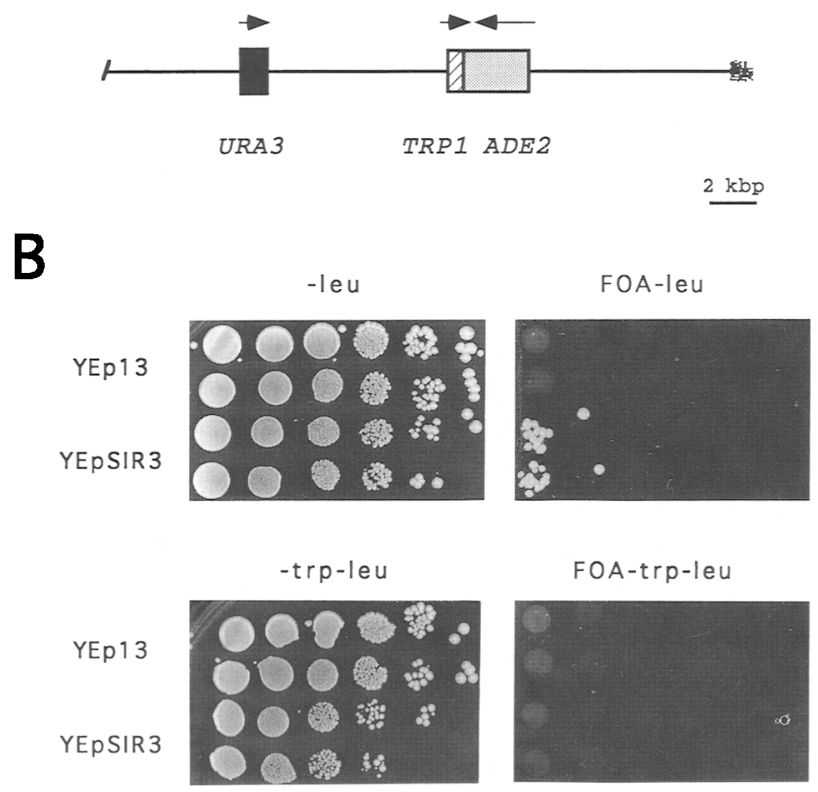

Figure 6. SIR 3 propagates continuous silenced domains from the telomere. (A) A sketch of the VII-L arm in UCC1035 is shown. The shaded and solid boxes represent ADE2 and URA3, respectively; the hatched box corresponds to the TRP1 gene. The arrows indicate transcriptional orientation of the inserted genes. The diffuse dark end, which represents the telomeric $\left(\mathrm{TG}_{1-3}\right)_{\mathrm{n}}$ repeat, is not drawn to scale. $(B)$ Plating efficiency of two independent isolates of UCC1035 transformed by YEpSIR3 or YEp13. Cells were pregrown in - leu media to maintain the plasmids. Tenfold serial dilutions were plated onto medium lacking leucine $(-$ leu). In addition, these plates either lacked tryptophan (-trp-leu), contained 5-FOA (FOA-leu), or lacked tryptophan and contained 5-FOA (FOA - trp-leu).

order reaction, then the occurrence of a repressed URA3 gene at $1 \mathrm{kbp}$ from the telomere would be expected six times as frequently as when $U R A 3$ is $6 \mathrm{kbp}$ away. From our results, this clearly is not the case. An exponential function more aptly describes the relationship between frequency of silencing and distance from the telomere (Fig. 2). Rather, the data suggest that telomeric silencing results from the cooperative assembly of subunits, and/ or assembly of multiple components. Such a multimeric representation of silent chromatin is not surprising, as it is expected to involve the four core histones plus additional components (Eissenberg 1989; Henikoff 1990; Spradling and Karpen 1990; Grigliatti 1991). Nevertheless, this work provides the first in vivo quantitative examination of the silent chromatin assembly process.

It has been proposed that specific terminator sequences along the chromosome act as barriers to heterochromatic spreading (Tartof et al. 1984). No such regions were detected on the telomere-proximal $16 \mathrm{kbp}$ of V-R, nor over the $20 \mathrm{kbp}$ of a modified VII-L (Figs. 3 and 6), although our data do not rule out the existence of such sites in yeast.

Cells carrying URA3 and HIS3 located near the V-R telomere, with HIS3 telomere-proximal, were unable to form colonies on FOA-his media (Fig. 5, UCC25762579). Because this medium selects for cells in which both URA3 is repressed and HIS3 is active, this result demonstrates that silent telomeric domains are continuously propagated from the end of the chromosome in yeast. Because a telomeric gene can be induced to become active (Gottschling et al. 1990; O.M. Aparicio and D.E. Gottschling, unpubl.|, we suggest that transcription may actively block silent chromatin propagation. Alternatively, transcription may not act as a barrier to the spread of silencing per se, but, rather, reflect that the silent telomeric domain assembled only a short distance from the telomere, thus never encompassing the HIS3 (or URA3) gene. The distinction between these two models should be considered regarding gene regulation within chromosomal domains.

\section{The role of the promoter in TPE spreading}

The presence of silent chromatin structures over a telomeric locus appears to impede the access of sequencespecific DNA-binding proteins to the DNA within, thereby generating a TPE (Gottschling et al. 1990; Aparicio et al. 1991; Gottschling 1992). The data plotted in Figure 2 show a steady decrease in the frequency of silencing when compared to the distance of the URA3 promoter from the telomere. This result strongly suggests that a gene's promoter is a major determinant in cis for effective transcriptional repression near telomeres. Combined with the finding that the silencing of $U R A 3$ does not appear to be dependent on the transcriptional orientation of $U R A 3$ (Fig. 2), we propose that repression is primarily exerted on the gene's promoter and therefore blocks initiation rather than elongation.

Two important points about position effect are provided by the experiments in which PPR 1 was deleted. As with most trans-activator proteins, PPR 1 appears to modulate transcription through the promoter (Roy et al. 1990). Hence, the increased frequency of telomeric silencing of $U R A 3$ in ppr $^{-}$strains supports the result that promoter occlusion is critical in achieving positioneffect repression (Fig. 2). These results also suggest that the spreading of position effect is a function of promoter strength of the gene being assayed.

A position effect on timing of replication has been detected at $\sim 35 \mathrm{kbp}$ from the V-R telomere (Ferguson et al. 1991; Ferguson and Fangman 1992), whereas position effect on $U R A 3$ transcription is not detected beyond $\sim 13$ kbp from the same terminus (Fig. 2). At present, we cannot resolve whether this apparent discrepancy reflects differences between the two assays being used or inherent distinctions between the mechanisms of initiating replication and transcription.

\section{Effect of $Y^{\prime}$ elements on the spread of telomeric silencing}

It has been suggested that $\mathrm{Y}^{\prime}$ elements overcome telomere position effect (Greider 1992), because genes em- 
bedded into Y's are not transcriptionally repressed (Carlson et al. 1985; Louis and Haber 1990). However, our data argue that Y's do not block the spread of telomeric repression per se; we find that a 6.7-kbp $\mathrm{Y}^{\prime}$ element sustains a greater frequency of silencing than an equal length of unique chromosomal sequences (Figs. 2 and 3A). It is unclear whether $Y^{\prime} s$ are involved in propagation or reinitiation of silencing or whether Y's simply lack elements present in unique chromosomal DNA that suppress the spreading of telomere-dependent transcriptional inactivation. Nevertheless, the presence of a $\mathrm{Y}^{\prime}$ element adjacent to a telomere results in a more extensive silent chromosomal domain. Perhaps this trait is important in maintaining the unique telomeric presence of $\mathrm{Y}^{\prime}$ elements.

\section{SIR3 enhances position effect in yeast}

Overexpression of SIR3 enhances position-effect variegation of telomeric genes; this SIR3 effect was also detected within and adjacent to the $H M$ loci $(\mathrm{H}$. Renauld and D.E. Gottschling, unpubl.). Thus, the modulation by SIR3 of position-effect repression is likely to occur at other places in the genome where an initiation site for SIR3-dependent silencing resides.

The slope of the observed gradient in frequency of $U R A 3$ silencing along V-R is altered by overexpressing SIR3 in the cell (Fig. 3A), suggesting that in contrast to the effect of a ppr1 mutation (Fig. 2), SIR3 overexpression affects silent chromatin rather than an intrinsic property of $U R A 3$. In addition, the increase in telomeric silencing is sensitive to SIR 3 gene dosage (Fig. 3B), indicating that SIR3 is limiting in the cell. These data suggest that SIR3 may be a structural component of yeast repressive chromatin or a factor directly required for its assembly. Alternatively, SIR3 may act indirectly by regulating the level or activity of structural or assembly constituents of silent chromosomal domains.

SIR3 bears no significant similarity to any known enhancers of position effects, such as the Drosophila Su(var)2-5 (HP-1) or Sulvar)3-7 proteins (Alberts and Sternglanz 1990) nor does it harbor a detectable chromodomain motif, which is thought to mediate the packaging of heterochromatin by the Su(var)2-5 and Polycomb gene products (Paro and Hogness 1991; Messmer et al. 1992). Extragenic suppressor analysis of $H M L$ silencing indicates a physical interaction between SIR3 and histone H4 (Johnson et al. 1990). Thus, we favor the model that SIR3 interacts directly with yeast nucleosomes to facilitate the compaction of chromatin into a higher-order structure responsible for silenced regions of the yeast genome. In this light, SIR3 may be a functional equivalent of histone $\mathrm{H1}$, mediating supranucleosomal organization of the genome (Weintraub 1984).

In addition to histone $\mathrm{H} 4$, telomeric silencing requires the products of SIR2, SIR4, NAT1, and ARD1. The roles of SIR2 and SIR4 in transcriptional repression are not yet clear. NAT1 and ARD1, which are subunits of an aminoterminal acetyltransferase (Park and Szostak 1992), presumably modify chromatin component(s) to facilitate as- sembly of repressed chromosomal states (Mullen et al. 1989; Park et al. 1992).

The ability of telomeric silencing to spread along the chromosome raises the question as to whether a cell can control the size of silenced domains. This issue is particularly critical for $S$. cerevisiae, in which inappropriate regional silencing might have immediate deleterious effects, owing to the high density of genes along the chromosome (Olson 1991). A cis-acting element can act as a chromosome-specific barrier against the spread of silent domains [e.g., active transcription units (this work) or homologs of the Drosophila scs sequences (Kellum and Schedl 1992)]. On a cellular scale, limiting the amount of SIR3 in the cell could prevent excessive transcriptional inactivation of the entire genome. Because the SIR3 gene itself is located near a telomere (Ivy et al. 1985) and no essential gene has been found between SIR3 and the telomere (Basson et al. 1987; Brisco et al. 1987; Dietzel and Kurjan 1987; Mortimer et al. 1992), position-effect repression of the SIR3 locus would provide a plausible negative feedback mechanism for control of position-effect spreading in yeast. If telomeric chromatin spread as far as the SIR3 locus, transcription of SIR3 would be repressed, thus limiting further spreading of the repressive chromatin. In apparent contrast to the yeast genome, larger eukaryotic genomes are extensively heterochromatic. This may be the result of the presence of more abundant functional homologs of SIR3. Extensive but carefully controlled heterochromatization of chromosomes may play a major role in control of cellular differentiation and development in complex eukaryotes.

In summary, the spread of telomeric position effect in $S$. cerevisiae is modulated by numerous factors, including promoter distance from the telomere, promoter strength, transcriptional status of telomere-proximal genes, presence of $Y^{\prime}$ elements, and intracellular concentration of the SIR3 gene product. These results highlight the complexity of mechanisms employed in regional gene expression and the plasticity of the eukaryotic genome.

\section{Materials and methods}

Construction of plasmids

Chromosomal location and a brief restriction map of the V-R sequences used in this study are diagramed in Figure 1A. The set of plasmids used to insert the URA3 gene at various positions along V-R was constructed as follows, starting with plasmid $\mathrm{pB} 610 \mathrm{H}$ (a gift from C. Newlon, New Jersey Medical School, Newark). Plasmid pHSS6TG carries a telomeric repeat sequence [derived from pYTCA-2 (Gottschling et al. 1990)] inserted between the EcoRI and BamHI restriction sites of plasmid pHSS6 (Seifert et al. 1986). Orientation of the telomeric sequence is such that digestion of pHSS6TG with EcoRI will yield an end that is a substrate for telomere formation in yeast. A 7.3-kbp $B a m H I$ fragment from plasmid $\mathrm{pB} 610 \mathrm{H}$ (Fig. 1A) was ligated into the BamHI site of pHSS6TG. A 7.4-kbp NotI fragment of this new plasmid, carrying unique $V-R$ sequences adjacent to a telomeric $\left(\mathrm{TG}_{1-3}\right)_{\mathrm{n}}$ repeat, was cloned into the Not I site of $\mathrm{pVZ1}$ (Henikoff and Eghtedarzadeh 1987), generating pSC1. Plasmids pVURAH2 $|+|$ and pVRURAH2| | | were constructed by insert- 
ing a 1.2-kbp HindIII fragment containing URA3 into the $\mathrm{H}_{2}$ site of pSCl partially digested with HindIII (Fig. 1A). URA3 transcriptional orientation is denoted plus $|+|$ when transcription is toward the telomere and minus $(-)$ when toward the centromere. URA3 was cloned in a similar way into the $\mathrm{H}_{3}$ and $\mathrm{H}_{4}$ HindIII restriction sites, generating plasmids pVURAH3 $\mid+$, pVURAH 3 - -1 , pVURAH $4 \mid+1$, and pVURAH4 $1-1$, respectively.

The HIS3 gene was isolated from plasmid pHIS3 (Struhl 1985; Gottschling et al. 1990) by amplification using PCR (Innis et al. 1990), with the following primers: 5 ' oligo, 5' - CCGGATCCTGCCTCGGTAATGATTTTCATTTTTT-3'; 3' oligo, 5'-CCGGATCCTCTCGAGTTCAAGAGAAAAAAAAAGAAA-3'. Restriction sites for BamHI, which were placed at the ends of the oligonucleotides for convenient cloning, are underlined. Hence, we refer to this DNA segment as HIS3 BamHI fragment.

Plasmids used to test for discontinuity of silenced chromosomal domains along V-R were created as follows. pH1.5HIS $31+1$ and $\mathrm{pH} 1.5 \mathrm{HIS} 3|-|$ were constructed in two steps. First, a 1.5 kbp HindIII fragment of V-R chromosomal DNA (between $\mathrm{H}_{2}$ and $\mathrm{H}_{3}$; Fig. $1 \mathrm{~A}$ ) was inserted into the HindIII site of pHSS6 to generate plasmid pHSS6(1.5). pHSS6(1.5) was then digested with KpnI, blunt-ended, and ligated with the HIS3 BamHI fragment, which had its ends filled in. A two-step process was also required to construct plasmids pVRUH2 $(-|\mathrm{HR} 1|+)$ and pVRUH2 $\mid-1$ HR1(-) Plasmid pVURAH2 (-) was cut with XhoI and Sall, and recircularized by ligation; a blunt-ended HIS3 BamHI fragment was ligated into this plasmid that had been partially digested with EcoRI and blunted with T4 DNA polymerase. Plasmids pVRUH2 $|+| \mathrm{HR} 1|+|$ and pVRUH2| + |HR $1|-|$ were constructed following the same procedure. Plasmids pYAHIS4-2|-| were made by cloning the HIS3 BamHI fragment into the BamHI site of pYA4-2 (Walton et al. 1986).

Plasmid p $\triangle$ PPR1-HIS3 was constructed by replacing a $0.7-$ $\mathrm{kbp} B g l I I$ fragment containing the promoter region of PPR1 (Kammerer et al. 1984), in plasmid pUC8-PPR1 (a gift from R. Losson, CNRS-IBMC, Strasbourg, France), with a 1.85 -kbp BamHI fragment from plasmid pHIS3. In plasmid $\mathrm{p} \triangle \mathrm{PPR} 1$ ::LYS2 the same $B g I I I$ fragment was replaced by a blunt-ended 4.8 -kbp HindIII-XbaI fragment containing LYS2, isolated from pDP6 (Fleig et al. 1986).

Plasmid pVZ1 $\triangle G C N 4:: T R P 1$ carries a deletion in the translation initiation region of GCN4. Plasmid pB238 [a derivative of plasmid p164 (Hinnebusch 1985)| was digested with BamHI and $B g I I I$, and a $0.8-\mathrm{kbp} B a m H I$ fragment containing TRP1 from YDpW (Berben et al. 1991) was ligated into it. A SalI-EcoRI $3.2-\mathrm{kbp}$ fragment of the resulting plasmid was then ligated into pVZl digested previously with EcoRI and SalI, to create pVZ1 $\triangle$ GCN4::TRP1.

The plasmid pVZJL38TRP1|+|ADE2|-| was used to insert TRP1 and $A D E 2$ between $A D H 4$ and telomere VII-L. Plasmid pUC19-JL3 contains a 0.4-kbp EcoRI-HindIII fragment including the JL3 region from VII-L (Walton et al. 1986). This plasmid was digested with EcoRI, its ends were made blunt, and the linearized plasmid was treated with HindIII. The JL3 region was ligated into plasmid pVZ1 digested previously with HincII and HindIII. Plasmid pVZJL38 was constructed by digesting the resulting plasmid, pVZJL3, with SmaI and EcoRI; an $\sim 0.8$-kbp EcoRI-HindIII fragment from plasmid pUC19-JL8 (Walton et al. 1986), with only its HindIII end made blunt, was ligated into the plasmid. A 1.45-kbp EcoRI fragment from plasmid YRp7 containing the TRP1 gene (Struhl et al. 1979) was then inserted into this new plasmid, pVZJL38. The resulting plasmid, pVZJL38TRP1 $\mid+1$, was digested with BglII, and a $3.6-\mathrm{kbp}$ $B a m H I$ fragment containing $A D E 2$ was inserted /Gottschling et al. 1990). Plasmid pVZJL38TRP1 $|+| A D E 2(-)$ has ADE2 inserted in the opposite transcriptional orientation as TRP1.
YEpSIR3 (alias pKAN63; R.E. Esposito laboratory, The University of Chicago, IL/ carries a $\sim 7 \mathrm{kbp} \mathrm{BamHI} \mathrm{genomic} \mathrm{insert}$ containing SIR3 and flanking chromosomal sequences (Ivy et al. 1986) cloned into YEp13 (Broach et al. 1979). CEN-SIR3 (pHR62-16) contains a 3.7-kbp HpaI fragment of plasmid pKAN63, encompassing SIR3 and its putative transcriptional regulatory elements (Shore et al. 1984), inserted into the SmaI restriction site of plasmid pRS314 (Sikorski and Hieter 1989).

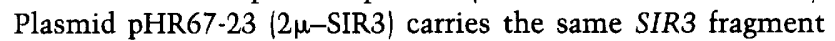
cloned into pHR59-33 $(2 \mu)$, a derivative of pRS424 (Christianson et al. 1992) in which the ClaI site was deleted.

Plasmid pHR49-1 was constructed by inserting a $1.2-\mathrm{kbp}$ $B a m H I$ fragment containing HIS3 from YDpH (Berben et al. 1991 ) into the BglII site of pRS316-SIR1 (a gift from Lorraine Pillus, University of Colorado, Boulder), which contains SIR1 and flanking genomic sequences. All other plasmids used for strain construction have been described previously (Ivy et al. 1986; Kimmerly and Rine 1987; Gottschling et al. 1990; Aparicio et al. 1991).

DNA manipulations were performed as reported previously (Sambrook et al. 1989; Gottschling et al. 1990). Escherichia coli strains MCl066 ( $\mathrm{r}^{-} \mathrm{m}^{-}$trpC9830 leuB600 pyrF::Tn5 lac $\Delta \mathrm{X} 74$ strA galU galK) (Casadaban et al. 1983), JF1754 ( $r^{-} \mathrm{m}^{-}$leuB met $B$ hisB) (Himmelfarb et al. 1987), and TG1 [supE hsd $\Delta 5$ this(lac-proAB) $F^{\prime}$ (traD36 proAB ${ }^{+}$lacI $^{q}$ lacZ $\Delta M 15$ )) (Sambrook et al. 1989) were used as plasmid hosts. Media for bacterial strains were prepared as described (Sambrook et al. 1989). Complementation of bacterial mutations by homologous yeast genes was used when applicable.

\section{Yeast strains and methods}

Media used for the growth of $S$. cerevisiae were described previously (Gottschling et al. 1990); all cultures were grown at $30^{\circ} \mathrm{C}$. Yeast transformation was performed by electroporation in the presence of sorbitol (Becker and Guarente 1991) or the lithium acetate procedure (Schiestl and Gietz 1989). 5-FOA resistance $\left(5-\mathrm{FOA}^{\mathrm{R}}\right)$ was determined as described previously (Aparicio et al. 1991). Yeast strain manipulations were carried out as described (Rose et al. 1990).

Strains UCC500-505 were constructed by transformation of YPH250 (Sikorski and Hieter 1989) with BamHI-digested plasmids pVURAH2 |+ |, pVURAH2|- |, pVURAH3|+1, pVURAH3|-1, pVURAH4 $(+)$, and pVURAH4 $(-)$, respectively. Strains UCC506-511 were constructed by transformation of strain YPH250 with the same plasmids digested with NotI. In both cases, $\mathrm{Ura}^{+}$colonies were selected. ppr $1^{-}$derivatives of these strains were constructed by transformation with EcoRI-digested $\mathrm{p} \triangle \mathrm{PPR} 1-\mathrm{HIS} 3$ and selection for $\mathrm{His}^{+}$transformants.

$U R A 3$ was inserted into the $A D H 4$ locus $(\sim 20 \mathrm{kbp}$ from telomere VII-L) of YPH250 to yield UCC1003, as described (Gottschling et al. 1990). UCC3248, UCC3249, and UCC3250 are derivatives of UCC1001 (Gottschling 1992) that are sir2::HIS3, sir3::HIS3, and sir4::HIS3, respectively, and were created by transformation as described (Kimmerly and Rine 1987; Aparicio et al. 1991). A sir 1::HIS3 derivative of UCC1003 (UCC3243) was constructed by transforming UCC1003 with ClaI- and SmaI-digested pHR49-1.

Plasmid pH1.5HIS3 $1+1$ was digested with NotI and transformed into UCC506 and UCC507 to make UCC2515 and UCC2517, respectively. pH1.5HIS3 - | was transformed in the same way into UCC506 and UCC507, to generate UCC2516 and UCC2518, respectively. Strains UCC2524-2527 were derived from YPH250 after transformation with the various pVRUH2|+/-|HR1|+/-| constructions digested with SphI and NotI. UCC1005 is derived from YPH250/Sikorski and Hie- 
Table 2. Yeast strains

\begin{tabular}{|c|c|c|}
\hline Strain & Relevant genotype & Origin \\
\hline LJY153 & MATa ade2 his3 leu2 lys2 trp1 ura3 hhfl::HIS3 & L. Johnson/M.Grunstein \\
\hline W303-la & MATa ade2 can1-100 his3 leu2 trp1 ura3-1 & R. Rothstein \\
\hline YPH250 & MATa ade2-101 his3- $\Delta 200$ leu2- $\Delta 1$ lys2-801 trp1- $\Delta 1$, ura3-52 & Sikorski and Hieter (1989) \\
\hline $\mathrm{UCCl} 16$ & W303-1a nat $1::$ LEU2 adh $4:: U R A 3-T E L$ & Aparicio et al. (1991) \\
\hline UCC18 & W303-1a adh4::URA3-TEL & Aparicio et al. (1991) \\
\hline UCC25 & W303-la ard1::LEU2 adh4::URA3-TEL & Aparicio et al. (1991) \\
\hline $\mathrm{UCC}(500-511)$ & YPH250 DIU5-(2-13) & this study \\
\hline $\mathrm{UCC}(512-523)$ & UCC(500-511) ppr1::HIS3 & this study \\
\hline UCC1001 & YPH 250 adh4::URA3-TEL & Gottschling (1992) \\
\hline $\mathrm{UCC} 1003$ & YPH250 adh4::URA3 & this study \\
\hline UCC1005 & YPH250 DIU5-1 & this study \\
\hline UCC1035 & UCC1003 DIA7-1 DIT7-1 & this study \\
\hline UCC2031 & LJY153 adh4::URA3-TEL & Aparicio et al. (1991) \\
\hline UCC2032 & LJY153 HHF2(gly-16) TRP1 adh4::URA3-TEL & Aparicio et al. (1991) \\
\hline UCC2033 & LJY153 HHF2(gln-16) TRP1 adh4::URA3-TEL & Aparicio et al. (1991) \\
\hline UCC2034 & LJY153 HHF2(gly-17) TRP1 adh4::URA3-TEL & Aparicio et al. (1991) \\
\hline UCC2576 & UCC507 gcn $4::$ TRP1 ppr1::LYS2 DIH5-1 & this study \\
\hline UCC 2577 & UCC507 gcn $4: \because$ TRP1 ppr1::LYS2 DIH5-2 & this study \\
\hline UCC 2578 & UCC506 gcn4::TRP1 ppr1::LYS2 DIH5-1 & this study \\
\hline UCC2579 & UCC506 gcn $4::$ TRP1 ppr1::LYS2 DIH5-2 & this study \\
\hline UCC2580 & UCC506 gcn4::TRP1 ppr1::LYS2 DIH5-3 & this study \\
\hline UCC2581 & UCC506 gcn $4:: T R P 1$ ppr $1:: L Y S 2$ DIH5-4 & this study \\
\hline UCC2582 & UCC507 gcn4::TRP1 ppr1::LYS2 DIH5-3 & this study \\
\hline UCC2583 & UCC507 gcn4::TRP1 ppr1::LYS2 DIH5-4 & this study \\
\hline UCC2589 & UCC1005 gcn4::TRP1 ppr1::LYS2 adh4::HIS3 & this study \\
\hline UCC2590 & YPH250 gcn4::TRP1 ppr1::LYS2 adh4::URA3-TEL DIH5-5 & this study \\
\hline UCC2591 & YPH250 gcn 4::TRP1 ppr1::LYS2 adh4::URA3 DIH5-5 & this study \\
\hline UCC3243 & UCC1003 sir1::HIS3 & this study \\
\hline UCC3248 & UCC1001 sir2::HIS3 & this study \\
\hline UCC3249 & UCC1001 sir3::HIS3 & this study \\
\hline UCC3250 & UCC1001 sir4::HIS3 & this study \\
\hline
\end{tabular}

The following convention was adopted to describe insertions of genes along a chromosome where no open reading frame or genetic locus has been mapped. Dominant mutant alleles of URA3 on chromosome $\mathrm{V}$ were designated DIU5 [directed integration of URA3 on chromosome $\mathrm{V}$ (in Arabic numerals)]. This convention was extended for insertion of ADE2, TRP1, or HIS3. The precise chromosomal structure of the relevant alleles is illustrated in Figs. 1B, 5, and 6A.

ter 1989) by transformation with pVR-URA3-TEL, as described (Gottschling et al. 1990). UCC1005 was transformed with pYAHIS4-2( - ) that had been digested with EcoRI and SalI, yielding strain UCC2509. Strain UCC2528 carries a telomeric URA3 at the VII-L telomere; it was created by transformation of YPH500 (Sikorski and Hieter 1989) with pVII-L URA3-TEL as described (Gottschling et al. 1990). The UCC2535 strain was created by transforming YPH250 with pVRUH2|-|HR $1|+|$, selecting for $\mathrm{His}^{+}$transformants, and then screening for $\mathrm{Ura}^{-}$cells. URA3 was integrated at the $A D H 4$ locus of UCC 2535 by transformation with padh4::URA3, as described (Gottschling et al. 1990), generating strain UCC2585. UCC2536, a meiotic segregant of a cross between UCC2528 and UCC2535, carries HIS3 on V-R and $U R A 3$ on VII-L. ppr1 $1^{-}$gcn $4^{-}$derivatives of strains UCC2515-2518, UCC2524-2527, UCC2509, UCC2536, and UCC2585 were constructed by transformation with EcoRI-digested p $\triangle$ PPR1::LYS2 and selection for Lys $^{+}$colonies; the GCN4 locus was then disrupted by transformation with pVZ1 $\triangle$ GCN4::TRP1 digested with NotI and SalI, yielding UCC2580-2583, UCC2576-2579, and UCC2589-2591. Chromosomal structures of these strains are diagramed in Figure 5.

The gamma-deletion method (Sikorski and Hieter 1989) was used to introduce TRP1 and ADE2 between the JL3 and JL8 regions on VII-L (Walton et al. 1986). Plasmid pVZJL38TRP1 + +
ADE2 | - | was digested with BamHI and transformed into UCC1003 to yield strain UCC1035.

The expected structures of the various chromosomal constructs were confirmed by Southern analysis as described previously (data not shown; Gottschling et al. 1990; Aparicio et al. 1991). All other strains have been described previously (Aparicio et al. 1991). Table 2 summarizes the relevant genotypes and origins of the strains used in this study.

\section{Acknowledgments}

We thank J. Aparicio, C. Atcheson, B. Berg, C. Fritze, S. Honigsberg, A. Kahana, R. McCarroll, M. Singer, and J. Stevenson for critical reading of the manuscript, and G. Berben, J. Broach, R. Esposito, A. Hinnebusch, R. Losson, C. Newlon, L. Pillus, J. Rine, and V. Williamson for yeast strains and plasmids. H.R. especially thanks F. Hilger for his continuous support during the progress of this work. This work was supported by grants from the Belgian Fonds National de la Recherche Scientifique and the NATO Scientific Committee to H.R., a National Science Foundation predoctoral fellowship to O.M.A., the Pew Charitable Trust, and National Institutes of Health grant GM43893 to D.E.G. 


\section{References}

Abraham, J., K.A. Nasmyth, J.N. Strathern, A.J.S. Klar, and J.B. Hicks. 1984. Regulation of mating-type information in yeast: Negative control requiring sequences both $5^{\prime}$ and $3^{\prime}$ to the regulated region. J. Mol. Biol. 176: 307-331.

Alberts, B. and R. Sternglanz. 1990. Chromatin contract to silence. Nature 344: 193-194.

Aparicio, O.M., B.L. Billington, and D.E. Gottschling. 1991. Modifiers of position effect are shared between telomeric and silent mating-type loci in S. cerevisiae. Cell 66: 12791287.

Baker, W.K. 1968. Position effect variegation. Adv. Genet. 14: 133-169.

Basson, M.E., R.L. Moore, J. O'Rear, and J. Rine. 1987. Identifying mutations in duplicated functions in Saccharomyces cerevisiae: Recessive mutations in HMG-CoA reductase genes. Genetics 117: 645-655.

Becker, D.M. and L. Guarente. 1991. High-efficiency transformation of yeast by electroporation. Methods Enzymol. 194: 182-187.

Berben, G., J. Dumont, V. Gilliquet, P.-A. Bolle, and F. Hilger. 1991. The YDp plasmids: A uniform set of vectors bearing versatile gene disruption cassettes for Saccharomyces cerevisiae. Yeast 7: 475-477.

Boeke, J.D., J. Trueheart, G. Natsoulis, and G.R. Fink. 1987. 5-Fluoroorotic acid as a selective agent in yeast molecular genetics. Methods Enzymol. 154: 164-175.

Brisco, P.R.G., T.S. Cunningham, and G.B. Kohlhaw. 1987. Cloning, disruption and chromosomal mapping of yeast LEU3, a putative regulatory gene. Genetics 115: 91-99.

Broach, J.R., J.N. Strathern, and J.B. Hicks. 1979. Transformation in yeast: Development of a hybrid cloning vector and isolation of the CAN1 gene. Gene 8: 121-133.

Brown, S.W. 1966. Heterochromatin. Science 151: 417-425.

Carlson, M., J.L. Celenza, and F.J. Eng. 1985. Evolution of the dispersed SUC gene family of Saccharomyces by rearrangements of chromosome telomeres. Mol. Cell. Biol. 5: 2894 2902.

Casadaban, M.J., A. Martinez-Arias, S.K. Shapira, and J. Chou. 1983. $\beta$-Galactosidase gene fusions for analyzing gene expression in Escherichia coli and yeast. Methods Enzymol. 100: 293-308.

Christianson, T.W., R.S. Sikorski, M. Dante, J.H. Shero, and P. Hieter. 1992. Multifunctional yeast high-copy-number shuttle vectors. Gene 110: 119-122.

Demerec, M. 1940. Genetic behavior of euchromatic segments inserted into heterochromatin. Genetics 25: 618-627.

Dietzel, C. and J. Kurjan. 1987. Pheromonal regulation and sequence of the Saccharomyces cerevisiae SST2 gene: A model for desensitization to pheromone. Mol. Cell. Biol. 7: 41694177.

Eissenberg, J.C. 1989. Position effect variegation in Drosophila: Towards a genetics of chromatin assembly. BioEssays 11: 14-17.

Feldman, J.B., J.B. Hicks, and J.R. Broach. 1984. Identification of sites required for repression of a silent mating type locus in yeast. J. Mol. Biol. 178: 815-834.

Ferguson, B.M., B.J. Brewer, A.E. Reynolds, and W.L. Fangman. 1991. A yeast origin of replication is activated late in $S$ phase. Cell 65: 507-515.

Ferguson, B.M. and W.L. Fangman. 1992. A position effect on the time of replication origin activation in yeast. Cell 68: 333-339.

Fleig, U.N., R.D. Pridmore, and P. Philippsen. 1986. Construction of LYS2 cartridges for use in genetic manipulations of
Saccharomyces cerevisiae. Gene 46: 237-245.

Gottschling, D.E. 1992. Telomere-proximal DNA in Saccharomyces cerevisiae is refractory to methyltransferase activity in vivo. Proc. Natl. Acad. Sci. 89: 4062-4065.

Gottschling, D.E., O.M. Aparicio, B.L. Billington, and V.A. Zakian. 1990. Position effect at $S$, cerevisiae telomeres: Reversible repression of PolII transcription. Cell 63: 751-762.

Greider, C.W. 1992. Telomere chromatin and gene expression. Curr. Biol. 2: 62-64.

Grigliatti, T. 1991. Position-effect variegation-An assay for nonhistone chromosomal proteins and chromatin assembly and modifying factors. Methods Cell Biol. 35: 587-627.

Haber, J.E. and J.P. George. 1979. A mutation that permits the expression of normally silent copies of mating-type information in Saccharomyces cerevisiae. Genetics 93: 13-35.

Heitz, E. 1928. Das Heterochromatin der Moose. I. Jahrb. Wiss. Bot. 69: 762-819.

Henikoff, S. 1990. Position-effect variegation after 60 years. Trends Genet. 6: 422-426.

Henikoff, S. and M.K. Eghtedarzadeh. 1987. Conserved arrangement of nested genes at the Drosophila GART locus. Genetics 117: 711-725.

Himmelfarb, H.J., E.M. Simpson, and J.D. Friesen. 1987. Isolation and characterization of temperature-sensitive RNA polymerase II mutants of Saccharomyces cerevisiae. Mol. Cell. Biol. 7: 2155-2164.

Hinnebusch, A.G. 1985. A hierarchy of trans-acting factors modulates translation of an activator of amino acid biosynthetic genes in Saccharomyces cerevisiae. Mol. Cell. Biol. 5: 2349-2360.

1988. Mechanisms of gene regulation in the general control of amino acid biosynthesis in Saccharomyces cerevisiae. Microbiol. Rev. 52: 248-273.

Hope, I.A. and K. Struhl. 1985. GCN4 protein, synthesized in vitro, binds HIS 3 regulatory sequences: Implications for general control of amino acid biosynthetic genes in yeast. Cell 43: $177-188$.

Hopper, A.K. and B.D. Hall. 1975. Mating type and sporulation in yeast. I. Mutations which alter mating-type control over sporulation. Genetics 80: 41-59.

Innis, M.A., D.H. Gelfand, J.J. Sninsky, and T.J. White. 1990. PCR Protocols: A guide to methods and applications. Academic Press, San Diego, CA.

Ivy, J.M., J.B. Hicks, and A.J.S. Klar. 1985. Map positions of yeast genes SIR1, SIR3 and SIR4. Genetics 111: 735-744.

Ivy, J.M., A.J.S. Klar, and J.B. Hicks. 1986. Cloning and characterization of four SIR genes of Saccharomyces cerevisiae. Mol. Cell. Biol. 6: 688-702.

Johnson, L.M., P.S. Kayne, E.S. Kahn, and M. Grunstein. 1990. Genetic evidence for an interaction between SIR3 and histone $\mathrm{H} 4$ in the repression of the silent mating loci in Saccharomyces cerevisiae. Proc. Natl. Acad. Sci. 87: 62866290.

Kammerer, B., A. Guyonvarch, and J.C. Hubert. 1984. Yeast regulatory gene PPR1. I. Nucleotide sequence, restriction map and codon usage. J. Mol. Biol. 180: 239-250.

Kayne, P.S., U.-J. Kim, M. Han, J.R. Mullen, F. Yoshizaki, and M. Grunstein. 1988. Extremely conserved histone H4 N terminus is dispensable for growth but essential for repressing the silent mating loci in yeast. Cell 55: 27-39.

Kellum, R. and P. Schedl. 1992. A group of scs elements function as domain boundaries in an enhancer-blocking assay. Mol. Cell. Biol. 12: 2424-2431.

Kimmerly, W.J. and J. Rine. 1987. Replication and segregation of plasmids containing cis-acting regulatory sites of silent mating-type genes in Saccharomyces cerevisiae are controlled 
by the SIR genes. Mol. Cell. Biol. 7: 4225-4237.

Klar, A.J.S., S. Fogel, and K. MacLeod. 1979. MAR1-A regulator of the HMa and HMo loci in Saccharomyces cerevisiae. Genetics 93: 37-50.

Klar, A.J.S., J.N. Strathern, J.R. Broach, and J. B. Hicks. 1981. Regulation of transcription in expressed and unexpressed mating type cassettes of yeast. Nature 289: 239-244.

Klar, A.J.S. , J.N. Strathern, and J.A. Abraham. 1984. Involvement of double-strand chromosomal breaks for mating-type switching in Saccharomyces cerevisiae. Cold Spring Harbor Symp. Quant. Biol. 49: 77-88.

Kostriken, R., J.N. Strathern, A.J.S. Klar, J.B. Hicks, and F. Heffron. 1983. A site-specific endonuclease essential for matingtype switching in Saccharomyces cerevisiae. Cell 35: 167174.

Laurenson, P. and J. Rine. 1992. Silencers, silencing, and heritable transcriptional states. Microbiol. Rev. 56: 543-560.

Lewis, E.B. 1950. The phenomenon of position effect. $A d v$. Genet. 3: 73-115.

Lima-de-Faria, A. 1983. Processes of directing expression, mutation and rearrangements. In Molecular evolution and organization of the chromosome (ed. A. Lima-de-Faria), pp. 507-604, Elsevier Science Publishers B. V., Amsterdam, The Netherlands.

Loison, G., R. Losson, and F. Lacroute. 1980. Constitutive mutants for orotidine 5 phosphate decarboxylase and dihydroorotic acid dehydrogenase in Saccharomyces cerevisiae. Curr. Genet. 2: 39-44.

Louis, E.J. and J.E. Haber. 1990. Mitotic recombination among subtelomeric $\mathrm{Y}^{\prime}$ repeats in Saccharomyces cerevisiae. Genetics 124: 547-559.

Mahoney, D.J. and J.R. Broach. 1989. The $H M L$ mating-type cassette of Saccharomyces cerevisiae is regulated by two separate but functionally equivalent silencers. Mol. Cell. Biol. 9: 4621-4630.

Marshall, M., D. Mahoney, A. Rose, J.B. Hicks, and J.R. Broach. 1987. Functional domains of SIR4, a gene required for position effect regulation in Saccharomyces cerevisiae. Mol. Cell. Biol. 7: 4441-4452.

Mastrangelo, M.F., K.G. Weinstock, B.K. Shafer, A.-M. Hedge, D.J. Garfinkel, and J.N. Strathern. 1992. Disruption of a silencer domain by a retrotransposon. Genetics 131: 519-529.

Megee, P.C., B.A. Morgan, B.A. Mittman, and M.M. Smith. 1990. Genetic analysis of histone H4: Essential role of lysines subject to reversible acetylation. Science 247: 841845.

Messmer, S., A. Franke, and R. Paro. 1992. Analysis of the functional role of the Polycomb chromodomain in Drosophila melanogaster. Genes \& Dev. 6: 1241-1254.

Mortimer, R.K., C.R. Contopoulou, and J.S. King. 1992. Genetic and physical maps of Saccharomyces cerevisiae, Ed. 11. Yeast 8: 817-902.

Mullen, J.R., P.S. Kayne, R.P. Moerschell, S. Tsunasawa, M. Gribskov, M. Colavito-Shepanski, M. Grunstein, F. Sherman, and R. Sternglanz. 1989. Identification and characterization of genes and mutants for an $\mathrm{N}$-terminal acetyltransferase from yeast. $E M B O$ I. 8: 2067-2075.

Nasmyth, K.A. 1982. The regulation of yeast mating-type chromatin structure by SIR: An action at a distance affecting both transcription and transposition. Cell 30: 567-578.

Nasmyth, K.A., K. Tatchell, B.D. Hall, C. Astell, and M. Smith. 1981. A position effect in the control of transcription at yeast mating type loci. Nature 289: 244-250.

Olson, M.V. 1991. Genome structure and organization in Saccharomyces cerevisiae. In The molecular and cellular biology of the yeast Saccharomyces (ed. J.R. Broach, J.R. Pringle, and E.W. Jones), Vol. 1, pp. 1-39, Cold Spring Harbor Laboratory Press, Cold Spring Harbor, New York.

Park, E.-C. and J.W. Szostak. 1990. Point mutations in the yeast histone $\mathrm{H} 4$ gene prevent silencing of the silent mating type locus HML. Mol. Cell. Biol. 10: 4932-4934.

- 1992. ARD1 and NAT1 proteins form a complex that has N-terminal acetyltransferase activity. EMBO $J$. 11: 2087-2093.

Park, E.-C., D. Finley, and J.W. Szostak. 1992. A strategy for the generation of conditional mutations by protein destabilization. Proc. Natl. Acad. Sci. 89: 1249-1252.

Paro, R. and D.S. Hogness. 1991. The Polycomb protein shares a homologous domain with a heterochromatin-associated protein of Drosophila. Proc. Natl. Acad. Sci. 88: 263-267.

Rine, J. and I. Herskowitz. 1987. Four genes responsible for a position effect on expression from $H M L$ and $H M R$ in Saccharomyces cerevisiae. Genetics 116: 9-22.

Rose, M.D., F. Winston, and P. Hieter. 1990. Methods in yeast genetics: A laboratory course manual. Cold Spring Harbor Laboratory Press, Cold Spring Harbor, New York.

Roy, A., F. Exinger, and R. Losson. 1990. cis- and trans-Acting regulatory elements of the yeast URA3 promoter. Mol. Cell. Biol. 10: 5257-5270.

Sambrook, J., E.F. Fritsch, and T. Maniatis. 1989. Molecular cloning: A laboratory manual, 2nd ed. Cold Spring Harbor Laboratory Press, Cold Spring Harbor, New York.

Sandell, L.L. and V.A. Zakian. 1992. Telomeric position effect in yeast. Trends Cell Biol. 2: 10-14.

Schiestl, R.H. and R.D. Gietz. 1989. High efficiency transformation of intact yeast cells using single stranded nucleic acids as a carrier. Curr. Genet. 16: 339-346.

Schnell, R. and J. Rine. 1986. A position effect on the expression of a tRNA gene mediated by the SIR genes in Saccharomyces cerevisiae. Mol. Cell. Biol. 6: 494-501.

Seifert, H.S., E.Y. Chen, M. So, and F. Heffron. 1986. Shuttle mutagenesis: A method of transposon mutagenesis for Saccharomyces cerevisiae. Proc. Natl. Acad. Sci. 83: 735-739.

Shore, D., M. Squire, and K.A. Nasmyth. 1984. Characterization of two genes required for the position effect control of yeast mating-type genes. EMBO J. 3: 2817-2823.

Sikorski, R.S. and P. Hieter. 1989. A system of shuttle vectors and yeast host strains designed for efficient manipulation of DNA in Saccharomyces cerevisiae. Genetics 122: 19-27.

Singh, I. and A.J.S. Klar. 1992. Active genes in budding yeast display enhanced in vivo accessibility to foreign DNA methylases: A novel in vivo probe for chromatin structure in yeast. Genes \& Dev. 6: 186-196.

Spofford, J.B. 1976. Position-effect variegation in Drosophila. In The genetics and biology of Drosophila (ed. M. Ashburner and E. Novitski), Vol. 1C, pp. 955-1018, Academic Press, New York.

Spradling, A.C. and G.H. Karpen. 1990. Sixty years of mystery. Genetics 126: 779-784.

Stone, E.M., M.J. Swanson, A.M. Romeo, J.B. Hicks, and R. Sternglanz. 1991. The SIR1 gene of Saccharomyces cerevisiae and its role as an extragenic suppressor of several mating-defective mutants. Mol. Cell. Biol. 11: 2253-2262.

Struhl, K. 1985. Nucleotide sequence and transcriptional mapping of the yeast pet56-his3-ded1 gene region. Nucleic Acids Res. 13: 8587-8601.

Struhl, K., D.T. Stinchcomb, S. Scherer, and R.W. Davis. 1979. High-frequency transformation of yeast: Autonomous replication of hybrid DNA molecules. Proc. Natl. Acad. Sci. 76: 1035-1039.

Sussel, L. and D. Shore. 1991. Separation of transcriptional activation and silencing functions of the RAP1-encoded repres- 
sor/activator protein 1: Isolation of viable mutants affecting both silencing and telomere length. Proc. Natl. Acad. Sci. 88: 7749-7753.

Tartof, K.D., C. Hobbs, and M. Jones. 1984. A structural basis for variegating position effects. Cell 37: 869-878.

Walton, J.D., C.E. Paquin, K. Kaneko, and V.M. Williamson. 1986. Resistance to antimycin A in yeast by amplification of $A D H 4$ on a linear, $42 \mathrm{~kb}$ palindromic plasmid. Cell 46: $857-$ 863.

Weintraub, H. 1984. Histone-H1-dependent chromatin superstructures and the suppression of gene activity. Cell 38: 1727.

Whiteway, M., R. Freedman, S. Van Arsdell, J.W. Szostak, and J. Thorner. 1987. The yeast $A R D 1$ gene product is required for repression of cryptic mating-type information at the $H M L$ locus. Mol. Cell. Biol. 7: 3713-3722.

Wright, J.H., D.E. Gottschling, and V.A. Zakian. 1992. Saccharomyces telomeres assume a nonnucleosomal chromatin structure. Genes \& Dev. 6: 197-210.

Zakian, V.A. 1989. Structure and function of telomeres. Annu. Rev. Genet. 23: 579-604.

Zuckerkandl, E. 1974. Recherches sur les propriétés et l'activité biologique de la chromatine: A possible role of "inert" heterochromatin in cell differentiation-Action of and competition for "locking" molecules. Biochimie 56: 937-954. 


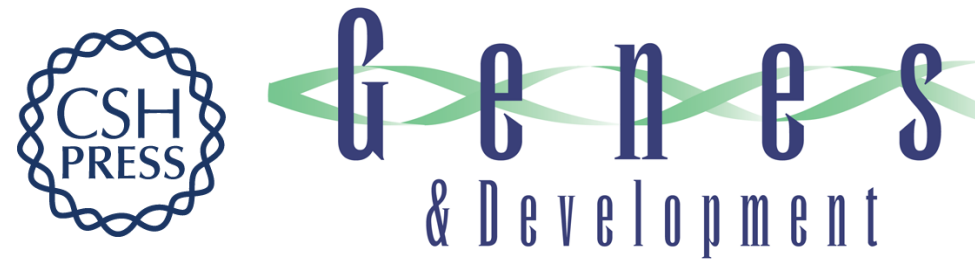

\section{Silent domains are assembled continuously from the telomere and are defined by promoter distance and strength, and by SIR3 dosage.}

H Renauld, O M Aparicio, P D Zierath, et al.

Genes Dev. 1993, 7:

Access the most recent version at doi:10.1101/gad.7.7a.1133

References This article cites 83 articles, 42 of which can be accessed free at:

http://genesdev.cshlp.org/content/7/7a/1133.full.html\#ref-list-1

License

Email Alerting

Service

Receive free email alerts when new articles cite this article - sign up in the box at the top right corner of the article or click here.

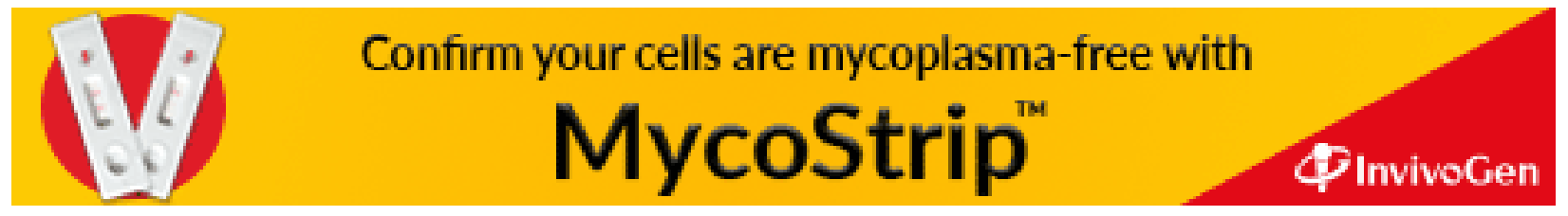

